\title{
CULTURAL SUSTAINABILITY AND EDUCATION, TWO INTERCONNECTED CONCEPTS: A CASE STUDY THE FESTIVALS OF RHODES
}

\author{
Dimitrios Matzanos ${ }^{1}$ and Yota Xanthacou ${ }^{2^{*}}$ \\ ${ }^{1}$ Dr., Post Doctoral, University of Aegean, Greece, matzanos@aegean.gr \\ ${ }^{2}$ Professor, University of Aegean, Greece, xanthakou@rhodes.aegean.gr \\ ${ }^{*}$ Corresponding Author
}

\begin{abstract}
The role of local festivals in the economic, social and cultural sustainability of communities has been highlighted in the international literature. Education plays an important role in maintaining and promoting them. Education is an essential tool for achieving sustainability. People around the world recognize that current economic growth trends are unsustainable and that public knowledge, education and understanding are the keys to achieving them.
\end{abstract}

Education for Sustainable Development aims to promote teaching that respects traditional knowledge, traditional local festivals and cultural heritage. In addition it promotes cultural sustainability and encourages the use of local languages in education. Local knowledge and local cultural heritage are the repositories of diversity and key resources for understanding the past and their continuation in the future of local communities. Festivals and local celebrations are factors that through education can be maintained and promoted, thus contributing to the cultural sustainability and sustainable development of local communities.

The present research aims to detect and record the knowledge and views of representatives of cultural institutions and citizens of the island of Rhodes on cultural sustainability and in particular on the sustainable development and evolution of festivals and folk festivals and the role of education in conservation, promotion and utilization of local festivals, fests and its role in the sustainable development of local communities.

It was a field research and the island of Rhodes in Greece was selected as a case study. The research took place during the period from November 2019 to February 2020. Semi-structured interviews were conducted. The sample was consisted of 50 representatives of cultural institutions and 50 citizens - residents of the villages of the island of Rhodes.

The results show that the representatives of the cultural institutions and the inhabitants of the villages are aware of the importance of the festivals and the folk festivals in the preservation of the cultural heritage. It is understood that the festivals and folk festivals contribute to the sustainable development of their area, both economically and environmentally, as they are presented informed and ready for their sustainable management. They consider the festivals to be a means of communication and information for both the local community and the wider region. The contribution of education is necessary for the better understanding and development of the local cultural sustainability.

They believe that the cultural sustainability and sustainable development of local communities can be achieved through formal education at all levels and most of them state that it is necessary to introduce and teach "special" courses on local history, local tradition and culture.

The results of the research are considered important and satisfactory, as they showed the need for preservation and sustainable development of festivals and folk festivals as a means of information and knowledge of local culture and folk tradition.

Keywords: Cultural Sustainability, Festivals, Education 


\section{INTRODUCTION}

The role of local festivals in the economic, social and cultural sustainability of communities has been highlighted in the international literature. Education plays an important role in maintaining and promoting them. Education is an essential tool for achieving sustainability. People around the world recognize that current economic growth trends are unsustainable and that public knowledge, education and understanding are the keys to achieving them (Matzanos et al, 2020).

The culture of each region, especially the local festivals and celebrations, leads to the conquest of the national self-knowledge of the inhabitants and their historical continuity. There they confirm their social cohesion, stimulate their local cultural self-confidence and feel moments of fullness (Pittas, 2013).

Sustainable handling of our cultural heritage is a task that requires special attention and sensitivity. The meeting of the past with the present, of the global with the local, of tradition with modernity can create new realities both in the field of art and social life (Pittas, 2013).

Sustainable event management (festivals, local festivals, festivals) is the process used to produce an event with particular concern for environmental, economic and social issues. The sustainability of the management of these events incorporates socially and environmentally responsible decisions for planning, organizing and implementing and participating in them. It includes the inclusion of sustainable development principles and practices at all levels of event organization and aims to ensure that an event can be held responsibly (Honabarger, 2011).

Festivals serve many purposes. Today, the most important is the local economic, social, cultural and often the political development of an area. Perhaps for this reason, a well-known scientist of events and especially of festivals, Getz (2009) defines the latter as a celebration of the values, ideology, identity and continuity of a community. The definition also includes the purposes. According to Getz, (2009) the purpose of the festivals is the continuation of tradition, which is defined by the ideology and values that compose the particular identity of a region (Getz, 2009).

Getz, (2009) and Gibson \& Wong (2011) have highlighted the role that local celebrations play in the economic, social and cultural sustainability of communities. Education plays an important role in maintaining and promoting them (Lin, Wackernagel, Galli \& Kelly, 2015).

Education for Sustainable Development aims to promote teaching that respects traditional knowledge, traditional local festivals, cultural heritage and encourages the use of local languages in education. Local knowledge and local cultural heritage are the repositories of diversity and key resources for understanding the environment and using it in the best possible way (Papavasileiou, 2015, p.123).

Education also plays a vital role in improving the quality of life. It increases the economic situation of the local community, improves the living conditions of the inhabitants and the educational achievement of the next generation, thus increasing the opportunities of the next generation for economic and social prosperity. Festivals and local festivals are factors that through education can be maintained and promoted, thus contributing to the cultural sustainability and sustainability of the local community (Mckeown, 2002; Mair et al, 2013).

Considering that sustainable development is an eminently creative and constructive process in the biological and cultural sense - create means perform a cultural act - (Glaveanu, 2011b, p. 18) we realize that it is a complex phenomenon, a product of social interaction and is co-constructed by the simultaneous management of the environmental, socio-cultural and economic resources of a community (Glaveanu, 2011).

Education is an essential tool for achieving sustainability. People around the world recognize that current economic growth trends are unsustainable and that public knowledge, education and understanding are the keys to achieving them. Beyond that there are small disagreements. People disagree about the meaning of sustainable development and whether it is achievable or not. There are different views on how unsustainable societies will be and how they will function. These same people are wondering why teachers have not moved quickly to develop education for sustainable development programs. Lack of agreement and definition has hampered efforts to develop Sustainable Development education (Mckeown, 2002).

The world needs educated and environmentally conscious citizens to help nations implement sustainability plans. All sectors- including business, industry, higher education, government, non-governmental organizations and community organization- are invited (encouraged) to train their environmental 
management leaders and provide education to their citizens (Mckeown, 2002).

Education is different from formation in that education is often specific to a particular job or class of tasks. Education teaches citizens how to use the means at their disposal safely, be more efficient and comply with regulations (eg environmental, health, or safety).

Education informs people about acceptable practices and procedures and gives them the skills to perform specific tasks. On the contrary, formation is a socially transformative process that gives people knowledge, skills, perspectives and values through which they can participate and contribute to their own well-being as well as to the well-being of their community and nation (Papavasileiou et al, 2017).

Education should include the entire formal education system - this includes universities, vocational schools (law and medicine) and technical schools along with primary and secondary education as well as the nonformal education system (Mckeown, 2002).

Thus, the necessity of the existence and cooperation of formal, non-formal and informal education in the whole range of education for the sustainable development and for the cultural viability of the local communities becomes clear (Papavasileiou et al, 2018).

\section{MAIN PART}

\subsection{Research Method}

The present research, which is part of a wider research, aims to detect and record the knowledge and views of representatives of cultural institutions and citizens of the island of Rhodes on cultural sustainability and in particular on the sustainable development and evolution of festivals and folklore and the role of education in the preservation, promotion and utilization of local festivals and festivals and its role in the sustainable development of local communities.

It was a field research and the island of Rhodes in Greece was selected as a case study. The research took place during the period from November 2019 to February 2020. Semi-structured interviews were conducted. The sample was consisted of 50 representatives of cultural institutions and 50 citizens - residents of the villages of the island of Rhodes.

In the present research, the connection of festivals and local collective holidays with the sustainable development of local communities and the role of education constitutes the general framework of problematic, important and originality, giving special weight and focusing on the views of cultural associations and citizens. of the island of Rhodes regarding whether education (formal, non-formal and informal) contributes to the preservation of cultural heritage and festivals as well as to economic, social, environmental and cultural sustainability.

This research was conducted exclusively by the researcher in the period from November 2019 to February 2020. The semi-structured interview was used as a methodological tool of the research, because each subject who participated had enough initiative in formulating his answers, the researcher limited minimal interventions, but also took care to direct the subject to talk about issues that the purpose of the research required to be covered during the available time (Bell, 1997). It was sampled in terms of the institutions of cultural associations and citizens of the island of Rhodes (50 bodies and 50 citizens).

The interviews in all the institutions of the cultural associations and the citizens were conducted (after the researcher had a telephone communication with the institutions) in their homes. The questions followed a general written outline that served as a reminder, but based on the principles governing the semi-structured interview, each participant was free to focus on points of interest, according to their own judgment and experience. All interviews were transcribed using a simple tape recorder and then transcribed and transcribed.

After transcribing the interviews, we proceeded to analyze the content of the responses of the representatives of cultural institutions and citizens and then categorize their responses into a limited number of independent categories. This was followed by the analysis of the research data of the interviews, the results were extracted and finally the conclusions were formulated.

\subsection{Description and Analysis of Results}

The survey includes a total of twenty-six (26) questions. This article presents five (5) questions that refer to the views of cultural associations and citizens of the island of Rhodes regarding the role of education in the preservation and promotion of festivals and their cultural sustainability. 
From the elaboration of the answers, as they were recorded from the interviews, the following results emerge, which, in the context of the present work, cannot be presented and commented in detail, so only some indications are given and in relation to the research axis regarding sustainability education in local communities.

In the first question about whether they believe that young people have the knowledge and the appropriate education to continue to keep the festivals of their place so as not to disappear in the future, $64.0 \%$ of respondents, according to the answers, believe that young people have the knowledge, compared to $36.0 \%$ of the sample stating that they do not have the appropriate knowledge.

The following question explores the views of representatives of cultural associations and citizens on how local events (festivals, etc.) could be maintained and whether this could be done through education. From the data of the answers it appears that $80 \%$ state that education can contribute to the maintenance of these events and even starting from Primary Education, while $20 \%$ of the respondents state that it cannot be done through education.

In the next question, on what kind of education should young people receive in order to continue the cultural heritage of their place and not to miss events such as festivals, $46.0 \%$ of the sample states formal education, $30.0 \%$ of the sample supports non-formal education, while $24.0 \%$ of the sample states non-formal education.

When asked about the conditions that must be met for the economic development of their area through the festivals, more than one answer was given, with the result that the total frequencies exceed the sample size. The data show that $66.0 \%$ of respondents state that the conditions that must be met for its economic development are first of all respect for tradition and the environment, $34.0 \%$ of the sample state the education of young people through schools, $14.0 \%$ support information and law enforcement, while $12.0 \%$ respond with purely financial criteria.

Finally, when asked about what needs to be done in terms of education in order for the preservation of cultural heritage and sustainable development to work successfully, $76.0 \%$ of the research sample state that there must be both Primary and Secondary Education, a special course that will teach local culture, customs and traditions in relation to sustainable development, compared to $24.0 \%$ of the sample that is differentiated and states that education does not play a big role in relation to the knowledge of older residents in informing young people.

\section{CONCLUSIONS - SUGGESTIONS}

Regarding the views of cultural institutions and citizens of the island of Rhodes on the role of education in the cultural sustainability of local communities, it becomes clear that the majority of institutions and citizens believe that young people have the necessary knowledge for cultural tradition. of their place as well as the appropriate education to continue to maintain the fests and local festivals of their place so as not to disappear in the future. It is observed that in recent years many young people from local communities participate in the organization of festivals as well as in their sustainable management.

Stakeholders and citizens believe that the promotion of local communities and their involvement in tourism through local festivals can be achieved with the help of education, in particular starting with primary education and introducing "special" courses in which local history, local tradition and culture are taught. It is worth noting that the majority of respondents consider it necessary to involve formal education at all levels.

Regarding the conditions that must be met for the sustainable development of their region through local festivals and fests, the majority of organizations and citizens state that in order to achieve sustainable development, first of all, respect for tradition and the environment and statements follow on the education of young people through schools as well as the updating and enforcement of laws. A small percentage of respondents answer with purely financial criteria.

In conclusion, it appears that the institutions of cultural associations and the citizens of the island of Rhodes believe that the cultural sustainability and sustainable development of local communities can be achieved through formal education and that they are informed and ready for the sustainable management of their areas.

The findings of Byers's research, Gunliffe \& Hudak (2001), lead to the conclusion that a strategy that combines cultural protection, knowledge of the specific features of the place and education, is more effective in highlighting and exploiting cultural heritage than a strategy that ignores traditional beliefs, values, institutions and education, thus confirming the common conclusions of our research.

Greece is one of the richest in the world in cultural tradition and culture. Festivals are also part of this tradition and culture. 
For the preservation, promotion and utilization of the festivals, the participation of the education is considered necessary. This can be achieved with special courses at all levels of education, where local history, local culture and tradition will be taught.

It is necessary the participation and active involvement of the local communities that with their special characteristics will shape the management framework of cultural events. This requires information, knowledge, as well as awareness and education about local events (local festivals, festivals, etc.) and their special characteristics, their structure, their operation and the measures required for their effective use.

The festivals should aim at both social and economic development. They should be a field where their values are highlighted and often used as a place of development, helping the local community to have economic and development benefits.

\section{REFERENCE LIST}

Bell, J. (1997). Methodological Design of Pedagogical and Social Research. Athens: Gutenberg (in Greek)

Getz, D. (2009). Policy for sustainable and responsible festivals and events: Institutionalization of a new paradigm, Journal of Policy Research in Tourism, Leisure and Events, 1(1): 61-78

Gibson, C. \& Wong, C. (2011). Greening rural festivals: Ecology, sustainability and human-nature relations, in C. Gibson \& J. Connell (eds) Festival Places: Revitalising Rural Australia. Clevedon: Channel View Puplications, pp.92-105

Glaveanu, V. P. (2011). Is the lightbulb still on? Social representations of creativity in a Western context. The International Journal of Creativity \& Problem Solving, 21(1), 53-72.

Honabarger, D. (2011). Bridging the Gap: The Connection Between Environmental Awareness, Past Environmental Behavior and Green Purchasing. (Master Thesis). American University, Washington DC

Lin, D., Wackernagel, M., Galli, A., \& Kelly, R. (2015). Ecological Footprint: Informative and evolving - A response to van den Bergh and Grazi (2014). Ecological Indicators

Mair, J., \& Whitford, M. (2013). An exploration of events research: Event topics, themes and emerging trends, International Journal of Events and Festival Management

Matzanos, D. \& Xanthacou, Y. (2020). Cultural sustainability and sustainable development: a case study of the Rhodes festivals, Proceedings of the 6th International Scientific Conference "Communication, information, information and education in late modernity", IAKE, Heraklion, 10-12 July 2020

McKeown, R. (2002). Education for Sustainable Development Toolkit.V2 p. 1-142. Waste Management Research and Education Institution (http://www.esdtoolkit.org).

Papavasileiou, V. (2015). Sustainable Development and Education: A multidimensional relationship. Athens: Diadrasi. (in Greek)

Papavasileiou, V., Nikolaou, E., Xanthacou, Y., Xanthis, A., Matzanos, D. \& Kaila, M. (2018). Organization pedagogical use of the spaces in the sustainable kindergarten: views of preschool education graduate students. IJAEDU- International E-Journal of Advances in Education, Vol. IV, Issue 12, 245250, http://ijaedu.ocerintjournals.org/download/article-file/615354

Papavasileiou, V., Nikolaou, E., Xanthacou, Y. Papadomarkakis, I., Matzanos, D. \& Kaila, M. (2017). Student preschool teachers' views about the pedagogical context of sustainable kindergarten. Proceedings of INTCESS 2017 4th International Conference on Education and Social Sciences. Istanbul, Turkey, 6-8 February, 2017

Pittas, G. (2013).Festivals in the Aegean. V. B. Athens: Lambraki Journalistic Organization, S.A. 